\title{
Tsunami Resonance in Palma Bay and Harbor, Majorca Island, as Induced by the 2003 Western Mediterranean Earthquake
}

\author{
J. Vela, ${ }^{1,2, \star}$ B. Pérez, ${ }^{1}$ M. González, ${ }^{3}$ L. Otero, ${ }^{3}$ M. Olabarrieta, ${ }^{3}$ \\ M. Canals, ${ }^{4}$ and J. L. Casamor ${ }^{4}$ \\ 1. Puertos del Estado, Avenida del Partenón 10, 28042 Madrid, Spain; 2. Qualitas Remos, Toronga 31, 28043 \\ Madrid, Spain; 3. Environmental Hydraulic Institute (Instituto de Hidráulica Cantabria), Universidad de \\ Cantabria, Escuela Técnica Superior de Ingenieros Caminos Canales y Puertos, Avenida los Castros s/n, 39005 \\ Santander, Spain; 4. Grup de Recerca Consolidat Geociències Marines, Departament d'Estratigrafia, \\ Paleontologia i Geociències Marines, Universitat de Barcelona, Campus de Pedralbes,
} Martí i Franquès s/n, 08020 Barcelona, Spain

\begin{abstract}
A B S T R A C T
The tsunami induced by the May 21, 2003, Algerian Boumerdès-Zemmouri earthquake (moment magnitude $M_{\mathrm{w}}=$ 6.9) propagated across the western Mediterranean Basin, thereby causing material damages in some harbors and coastal areas. This was the case in the Balearic Islands and particularly the Palma harbor. Attempts to simulate the 2003 tsunami event found discrepancies between tsunami arrival times and wave amplitude when comparing tide gauge records with results from numerical models. To date, all published model results of the amplitude of the tsunami are underestimations, attributed to numerical limitations due to the lack of high-resolution bathymetry and poor definition of harbor geometry. Other views suggest the inappropriateness of the available seismic source parameterizations and the possible occurrence of submarine landsliding triggered by the earthquake that has not been included in the numerical simulations. In this article we present the results of a numerical study aimed at better understanding the response of the interacting Palma bay and harbor under the impact of the 2003 western Mediterranean tsunami. The transference of the tsunami energy from the generation area to the continental shelf, the bay, and the harbor has been studied and compared with the natural oscillation modes of the bay and harbor water bodies. Our work includes a sensitivity analysis of the source parameterization and the bathymetry grid size for the bay and harbor as a way to explain the discrepancies between simulations and observations. The Palma harbor tide gauge shows that energy from the tsunami concentrated mainly in periods that fitted to the natural modes of oscillations of the bay. Therefore, the significant wave amplification observed inside the harbor, mainly in its northern basin, was generated by a resonance effect induced by Palma bay. The improvement of the bathymetry grid resolution in the bay and harbor domains and the inclusion in the simulations of the exact harbor geometry and internal configuration result in a slight wave-high increment that is much below the wave height recorded in the tide gauge. Our results strongly point to a necessary revision of the tsunami seismic source parameters.
\end{abstract}

\section{Introduction}

Nontidal oscillations with periods of several minutes caused by meteorological disturbances are rather common in narrow embayments and harbors of the western Mediterranean Sea, especially in the Balearic Islands (Montserrat et al. 2006; Jansa et al. 2007). These oscillations may cause significant material damage and seriously alter the normal op-

Manuscript received November 13, 2012; accepted November 26, 2013; electronically published March 14, 2014.

* Author for correspondence; e-mail: jordivela@gmail.com. eration of the harbors. This study focuses on the $250-\mathrm{km}^{2}$ Palma bay to the west of Majorca Island and on the $2.6-\mathrm{km}^{2}$ Palma harbor that occupies the northernmost corner of the bay (fig. 1).

A different type of nontidal oscillation occurred in the Balearic Islands on May 21, 2003, when a small tsunami (referred from here onward as the 2003 western Mediterranean tsunami) struck the islands' shores and coastal infrastructures after an earthquake in offshore Algeria, known as the Boumerdès-Zemmouri earthquake. The earthquake oc- 


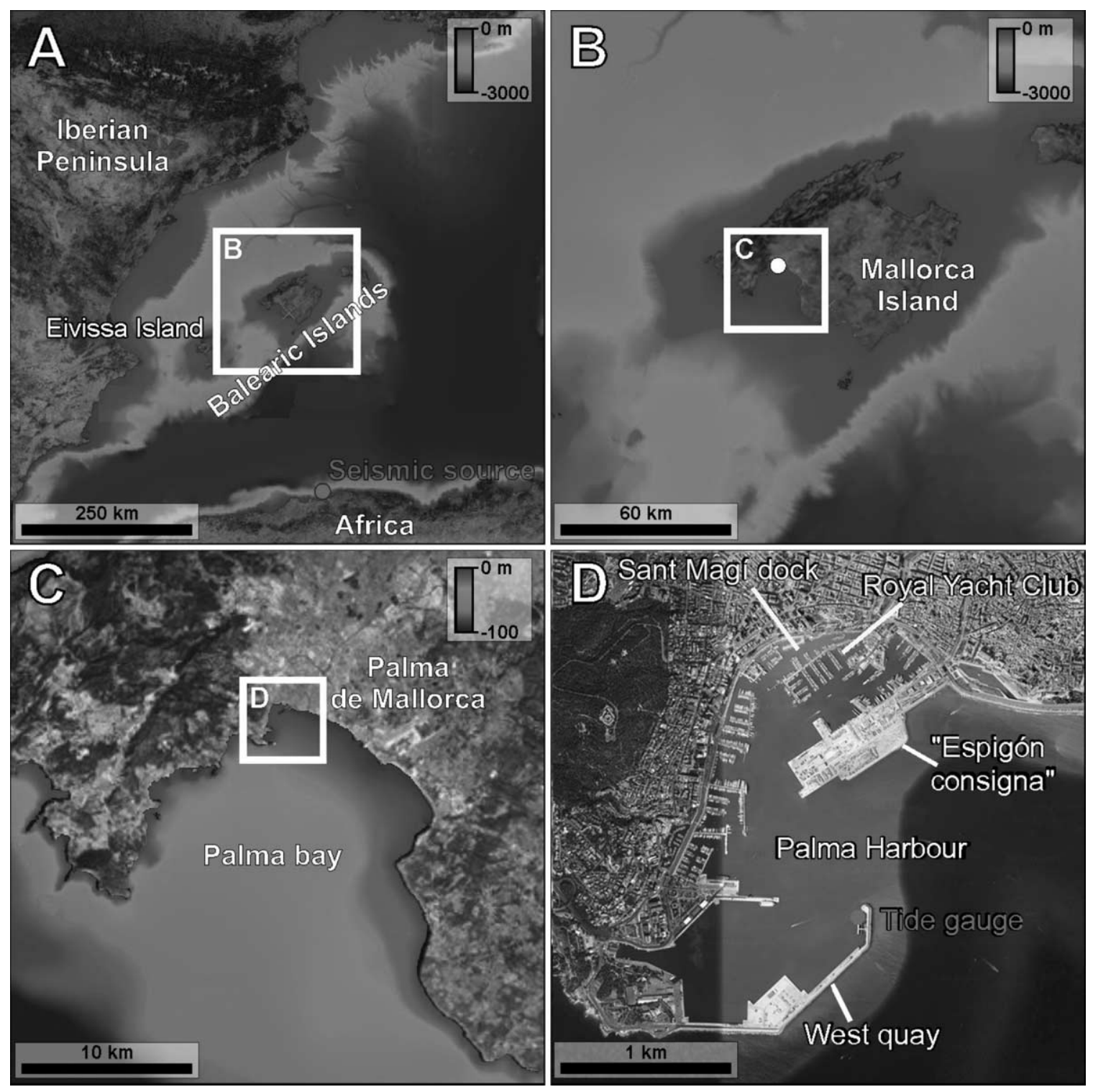

Figure 1. Nested maps of the study area. $A$, General map of the western Mediterranean Basin (in red in Meghraoui et al. 2004, seismic source). B, Map of the marine area surrounding Majorca Island. C, Map of Palma bay. D, Map of Palma harbor in the northernmost dead end of the bay. A color version of this figure is available online.

curred as a consequence of the subduction of the Eurasian plate under the African plate. Initial estimates of the earthquake parameters indicate that it started at 18:44:30 UTC, with the epicenter at lat $36^{\circ} 93^{\prime} \mathrm{N}$, long $3^{\circ} 58^{\prime} \mathrm{E}$ and an initial moment magnitude $\left(M_{\mathrm{w}}\right)$ of 6.8 according to the Harvard Central Moment Tensor (CMT) solution.

Several generation mechanisms have been suggested for the Boumerdès-Zemmouri earthquake, leading to different source parameters. Field studies by Meghraoui et al. (2004) and teleseismic wave analysis studies by Yagi (2003) suggest that the magnitude of the earthquake likely was stronger than the initial estimate. Wang and Liu (2005), Alasset et al. (2006), and, more recently, Sahal et al. (2009) have performed numerical simulations of the event.

Wang and Liu (2005) utilized the Harvard CMT and Meghraoui et al. (2004) generation mechanisms to simulate the 2003 western Mediterranean tsunami and focused on Eivissa city and Sant Antoni harbors, both in the island of Eivissa (fig. 1A). Their results indicated that Meghraoui et al. (2004) presented better tsunami wave height predictions than those achieved with the Harvard CMT, although both were underestimated compared with tide 
A)

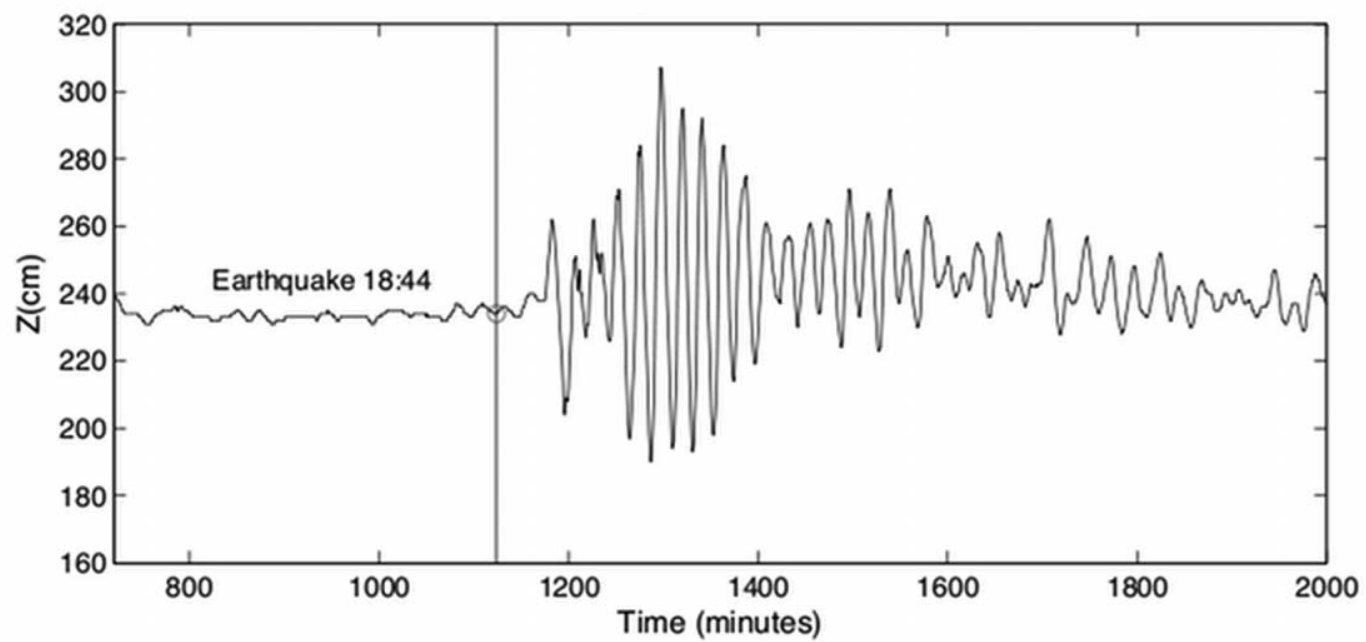

B)

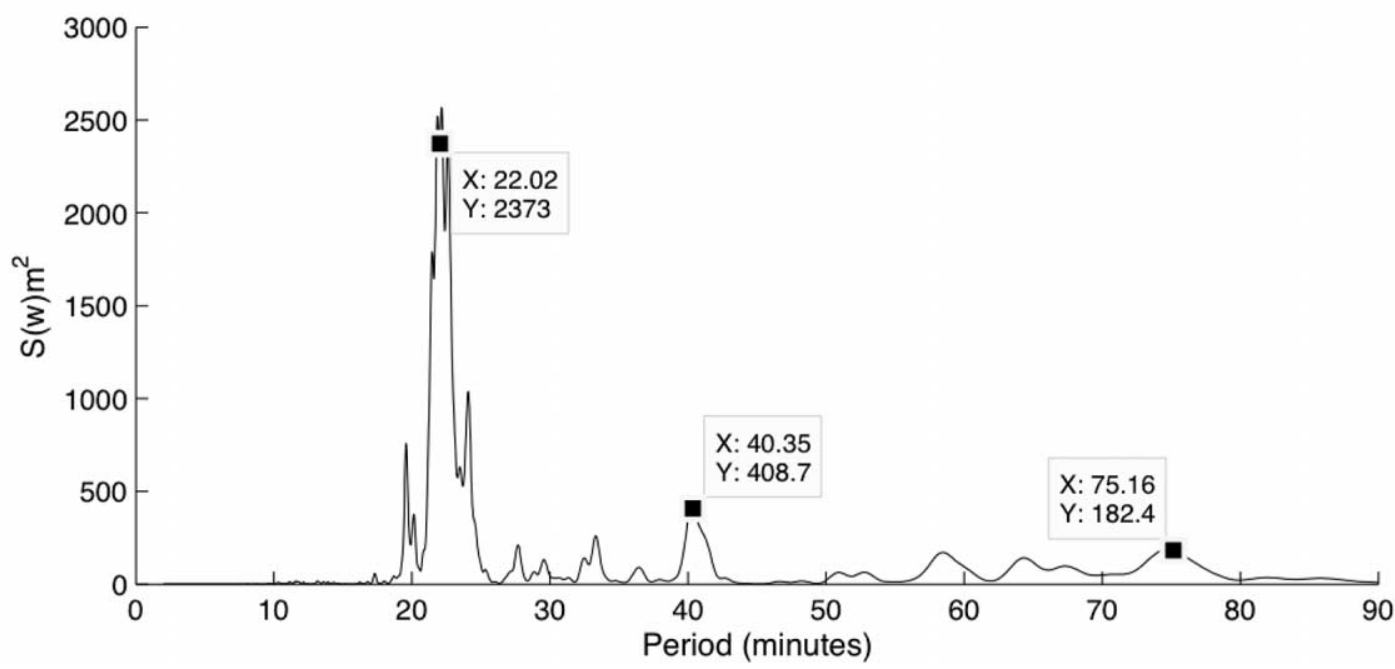

Figure 2. A, Sea level oscillations during the 2003 western Mediterranean tsunami recorded in the Palma tide gauge. Time in minutes from 2400 hours of May 21. Sampling interval is $1 \mathrm{~min}$. B, Spectral density of the Palma tide gauge record during the 2003 western Mediterranean tsunami.

gauge data. The numerical simulations considered a high-resolution bathymetry of the source area with up to $10-\mathrm{m}$ grid size uncertainty for the fault plane. Using an inversion method supplied with the tide gauge data from Sant Antoni, Wang and Liu (2005) were able to improve the fault plane model, which was further validated with the data from Eivissa city. The new fault plane model suggested a stronger earthquake $\left(M_{\mathrm{w}}=7.2\right)$ with larger seafloor uplift.

Alasset et al. (2006) aimed at elucidating whether the tsunami in the Balearic Islands resulted from a combination of the earthquake-generated tsunami and a contribution by a landslide in the Algerian margin, but examination of the $T$ waves did not show evidence of the latter. However, Dan (2007) reported 29 submarine cable breaks off of Algeria caused by generalized submarine landsliding along at least $170 \mathrm{~km}$ of the continental slope that occurred $36 \mathrm{~min}$ to $3 \mathrm{~h} 49 \mathrm{~min}$ after the main earthquake shock. Alasset et al. (2006) tried five different seismic sources, with magnitudes from $M_{\mathrm{w}}=6.7$ to 7.1 and concluded that the sources of Meghraoui et al. (2004) and Delouis et al. (2004) were the ones that gave the best results for Palma, Eivissa, and Sant Antoni. Also, Alasset et al. (2006) noticed the difficulty of reproducing the exact amplitude and frequency response in Palma harbor due either to an effect of the low-resolution bathymetry or to a local phenomenon not included in the simulations, 


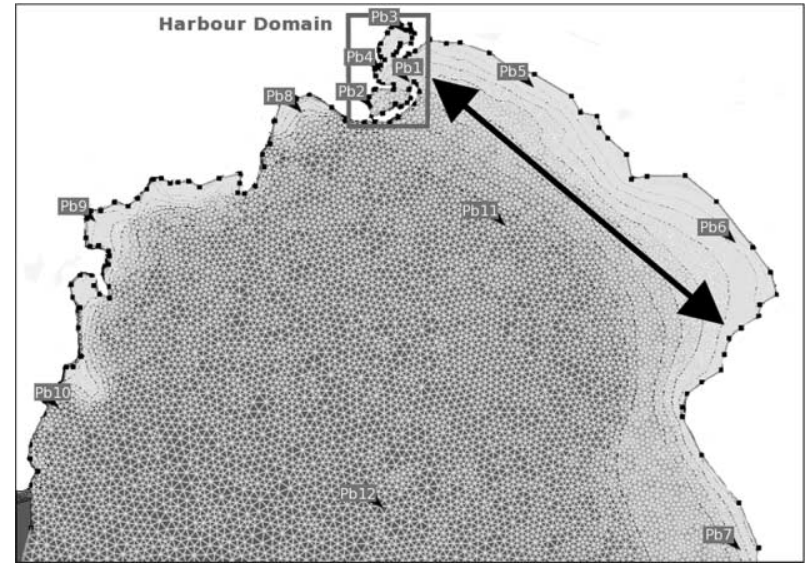

Figure 3. Domain used for Instituto de Hidráulica-mild slope simulations for Palma bay, with location of the selected synthetic points. Transverse local edge waves are indicated by the arrow. A color version of this figure is available online.

such as a misrepresentation of the geometry of the harbor or the physical properties of the quays.

Sahal et al. (2009) studied the effects of tsunamis along the French coast. The simulations showed a certain correlation between the field results and the wave amplification along the coast; however, it underestimated the observed phenomena, even by using high-resolution bathymetric grids (space step of $3 \mathrm{~m}$ ) centered in harbors. They concluded that the low sampling rate of the French tide gage records (10 min) did not allow for a proper evaluation of the tsunami wave amplitudes and emphasized the importance of having accurate and precise data about the source.

All tide gauges in the western Mediterranean Basin recorded the resulting sea level oscillations, with the largest amplitudes being detected at Palma and Sant Antoni harbors, in the islands of Majorca and Eivissa, respectively. The first crest of the small tsunami reached the Palma tide gauge 51 min after the earthquake, at 19:35 UTC. The initial amplitude was of $\sim 20 \mathrm{~cm}$ and $110 \mathrm{~min}$ later increased to $55 \mathrm{~cm}$, thus yielding a total amplitude of $\sim 1.10 \mathrm{~m}$. The initial crest arrived at 19:45 at Sant Antoni, i.e., $61 \mathrm{~min}$ after the earthquake, with up to 1.10 $\mathrm{m}$ of total amplitude. At the harbor of Eivissa city, the first arrival was at 19:34 UTC, i.e., $1 \mathrm{~min}$ before Palma, with a total amplitude of $\sim 76 \mathrm{~cm}$, also peaking 110 min later. Sête, in southern France, detected the first arrival 126 min later at 20:50 UTC, though the amplitude was very small, as for the rest of the tide gauges in the region located at Barcelona, Valencia, Alacant, Ajaccio, Toulon, Marseille, Livorno, and other harbors. It is to be noted that the sampling frequency of the tide gauges ranged from $1 \mathrm{~min}$ (e.g., Palma) to $2 \mathrm{~min}$ (e.g., Sant Antoni and Sête) to even $5 \mathrm{~min}$ (e.g., Eivissa), which could lead to an underestimation of the tsunami amplitude for the latter.

The damages generated by the 2003 western Mediterranean tsunami in Palma harbor concentrated in the northern basin, where several pleasure and sailing boats sank between Sant Magí dock and the Royal Yacht Club (fig. 1). The shallow water depth in this part of the harbor eased the sinking of the boats, as they were quickly moved up and down by the oscillations, easily hitting the bottom and breaking. Also, the seaside promenade in this part of the harbor was severely affected by the tsunami. A second highly impacted area was the Espigón Consigna (literally meaning the "left-luggage office breakwater"), in the commercial quays, where the tsunami waves took down an oil container and other objects (fig. 1). Other harbors along the islands' shores reported significant material damage, especially Maó in Minorca Island, where, unfortunately, no sea level records are available. Noticeably, no relevant flooding was reported off the harbors.

It is thought that the damages reported in Palma harbor result from a resonance phenomenon with noticeable amplification of wave heights in its northern basin, which a priori is the most protected part of the harbor. Resonance is a well-known problem inside harbors that occurs when the natural oscillation mode associated with a determined eigenperiod is similar to the forcing period (Losada et al. 2008). The natural periods of oscillation depend on the water depth and the geometry of the body of water, so that the study of resonance effects

Table 1. Grids Utilized for the Simulation with the Cornell Multi-grid Coupled Tsunami Model (COMCOT) of Two Source Parameterizations of the 2003 Western Mediterranean Tsunami

\begin{tabular}{lcccccc}
\hline Grid & $\Delta x(\mathrm{~m})$ & $\Delta t(\mathrm{~s})$ & Nodes in $x$ & Nodes in $y$ & Theory & Roughness \\
\hline 01 & 720 & .2 & 1336 & 1336 & Linear & No \\
21 & 220 & .1 & 678 & 678 & Nonlinear & .001 \\
31 & 110 & .05 & 282 & 282 & Nonlinear & .001 \\
41 & 20 & .025 & 245 & 245 & Nonlinear & .001 \\
\hline
\end{tabular}




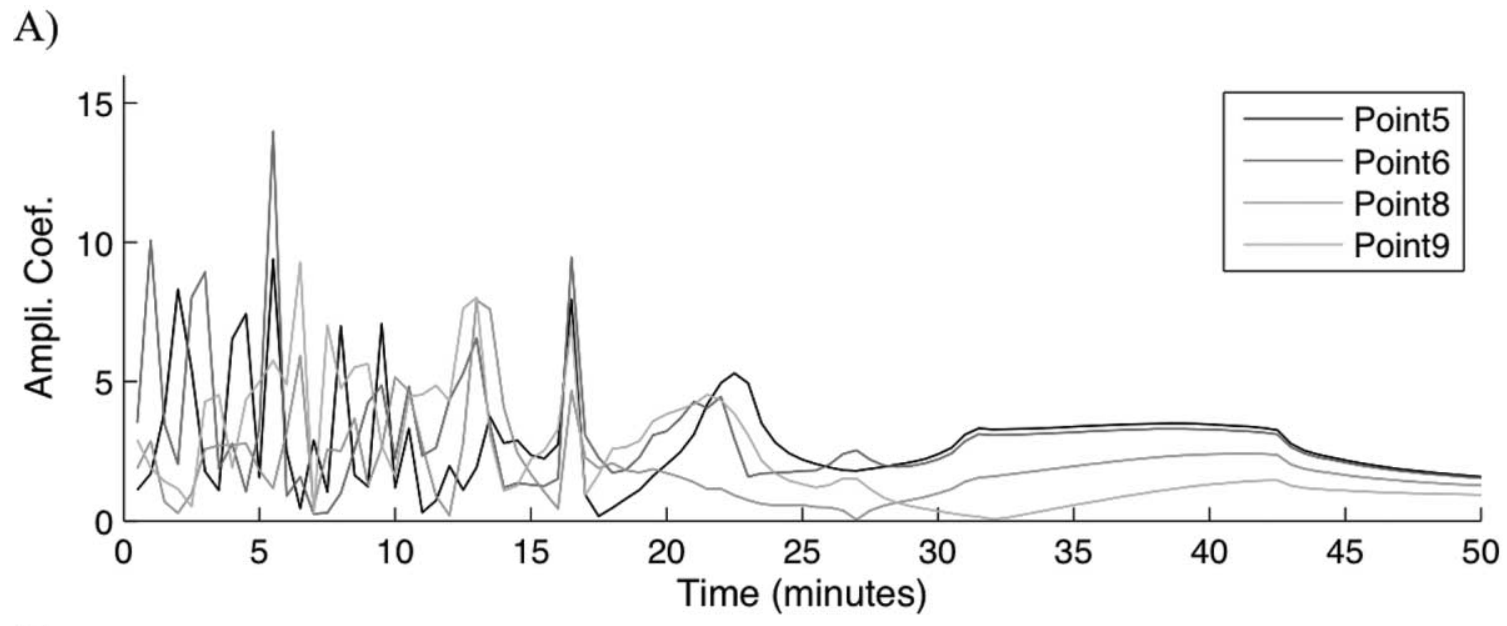

B)

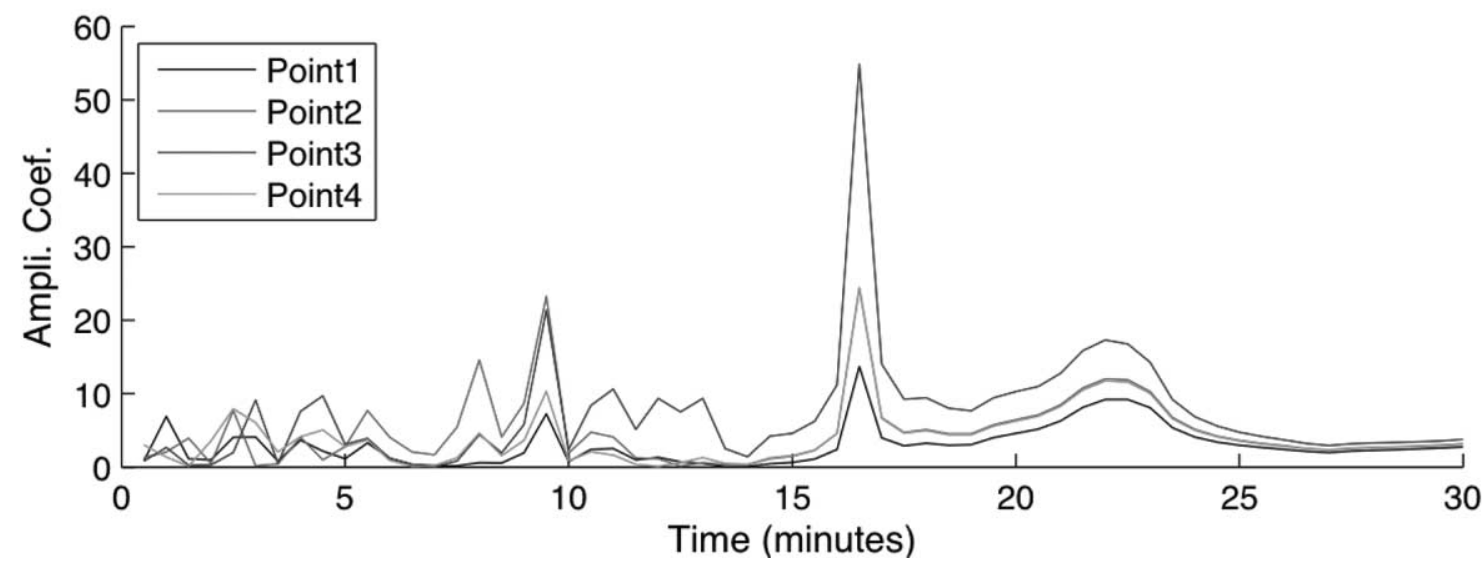

Figure 4. A, Output of the frequency-amplitude-swept simulations, at selected synthetic points in the Palma bay outside the harbor. $B$, Output of the frequency-amplitude-swept simulations at selected synthetic points in the Palma bay inside the harbor. A color version of this figure is available online.

in the bay and harbor of Palma using numerical simulations requires a high-resolution bathymetry and a well-defined geometry of the port.

While previous numerical simulations such as those of Wang and Liu (2005), Alasset et al. (2006), and Sahal et al. (2009) have brought considerable insight on this tsunami, all of them have failed in reproducing the exact amplitude of the oscillations and the subsequent resonance phenomena. Such a failure has been attributed to the lack of high-resolution local bathymetry and harbor geometries.

In this work, we investigate for Palma bay and harbor whether the above-mentioned failure results from numerical or physical reasons, taking advantage of the now available high-resolution bathymetries. To better understand the response of the harbor and its interaction with the larger bay, we have carried out some tests using the known Boumerdès-
Zemmouri seismic source, also trying different parameterizations. We have also applied a numerical model to perform a sensitivity analysis by changing the local resolution of the seafloor bathymetry, with the aim of shedding light on the discrepancies between simulations and observations. The comparison of simulations and observations has been eased by the availability of tide gauge records from seven Spanish ports. Overall, the Boumerdès-Zemmouri earthquake and associated western Mediterranean tsunami, and their impact on the Palma bay and harbor, constitute an interesting case for modeling experiments.

The work is focused mainly on the study of the frequency response of Palma harbor to tsunamis, with a special focus on the 2003 western Mediterranean tsunami. One of the main objectives is to verify a resonance phenomenon by analyzing the 
A)

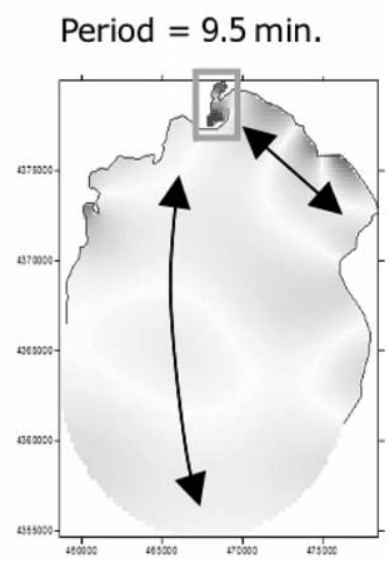

B)

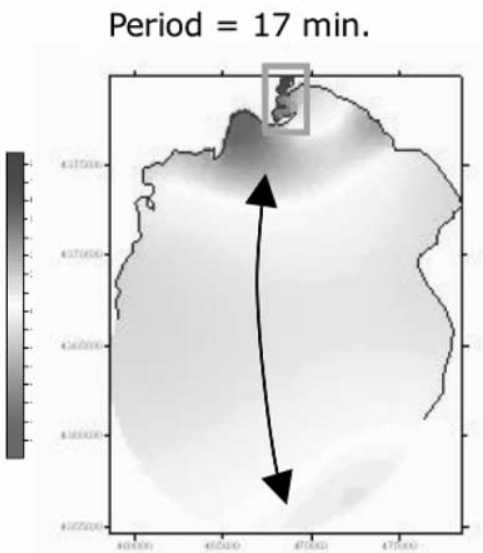

C)

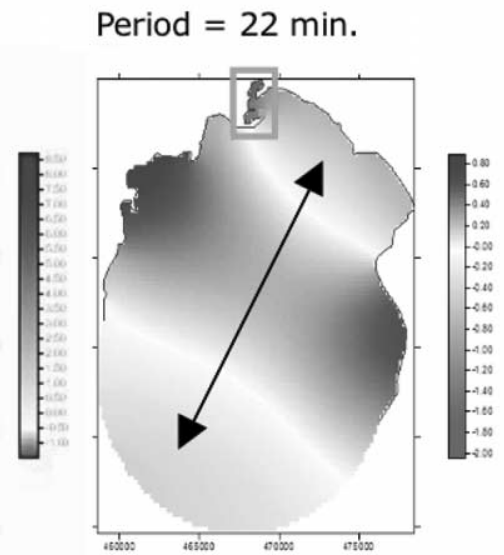

Figure 5. Spatial distribution of nodes and antinodes for the main modes of oscillation identified for Palma bay. The arrows indicate the main direction of the oscillation. Gray inset indicates harbor domain. Filled circles indicate tide gauge location. $A, 9.5-\mathrm{min}$ period. $B, 17-\mathrm{min}$ period. $C, 22-\mathrm{min}$ period. A color version of this figure is available online.

transfer of energy of the tsunami from the generation area to the bay and harbor, compared with the natural oscillation modes of both water bodies. Another scope of this work is the sensibility analysis regarding the influence of the grid size of the harbor and bay bathymetries for the numerical simulations of the 2003 tsunami event.

\section{Methodology}

The computation of the natural modes of resonance (eigenperiods) has been performed at different locations of the Palma harbor and bay by applying the Instituto de Hidráulica-mild slope (IH-MSP) model (Berkhoff 1972). The numerical simulation of the 2003 western Mediterranean tsunami has been carried out with the Cornell multi-grid coupled tsunami model (COMCOT) using Meghraoui et al. (2004) and Wang and Liu (2005), from where energy spectra were obtained for similar locations. The energy distribution by frequencies has been analyzed after comparing natural modes of oscillation and the oscillations generated by the 2003 tsunami. The sensibility analysis of the bathymetry resolution has been conducted on four different sets of grid sizes, with high-resolution bathymetry of Palma bay and harbor compiled within the European Union Tsunami Risk and Strategies for the European Region (TRANSFER) project. The water height and spectra at the tide gauge in Palma have been compared to the numerical simulations from COMCOT applying Meghraoui et al.'s (2004) source model.
The IH-MSP model is based on the mild slope equation of Berkhoff (1972), first developed by Berkhoff (1982) and Behrendt (1984) for studying wave propagation over bathymetries experiencing smooth variations. The version of the MSP model that we have used is the one further developed by IH Cantabria from the University of Cantabria, Spain, hence the acronym IH-MSP. The new model version solves the elliptic form of the equation for linear waves and allows including reflective, absorbing, and partly absorbing boundary conditions to define structures and breakwaters inside a harbor. The mild slope equation can be expressed as

$$
\nabla \Gamma C C_{g} \nabla \Phi+\frac{\omega^{2} C_{g}}{C} \Phi=0,
$$

where $\nabla=$ gradient operator $[\nabla=(\delta x, \delta y)], \Gamma=$ bottom friction coefficient, $C=$ local phase velocity $(C=w / k), C_{g}=$ group velocity $\left(C_{g}=\delta w / \delta k\right)$, $w=$ wave angular frequency $(w=2 \pi / T), T=$ wave period, $\Phi=$ velocity potential, $k=$ local wave number $\left(w^{2}=g k \tan h(k h)\right), g=$ gravitational acceleration, $h(x, y)=$ variable water depth, $a=$ wave amplitude, $x, y=$ coordinate axes.

Solving equation (1) requires defining the boundary conditions along the integration domain. The numerical solution of the elliptic equation applies a finite element scheme following Behrendt (1984) for a variable bottom.

Yalciner and Pelinovsky (2007) followed a similar procedure developing a new numerical method for evaluation of the modes of free oscillations of the basins that have irregular geometry, and they ob- 


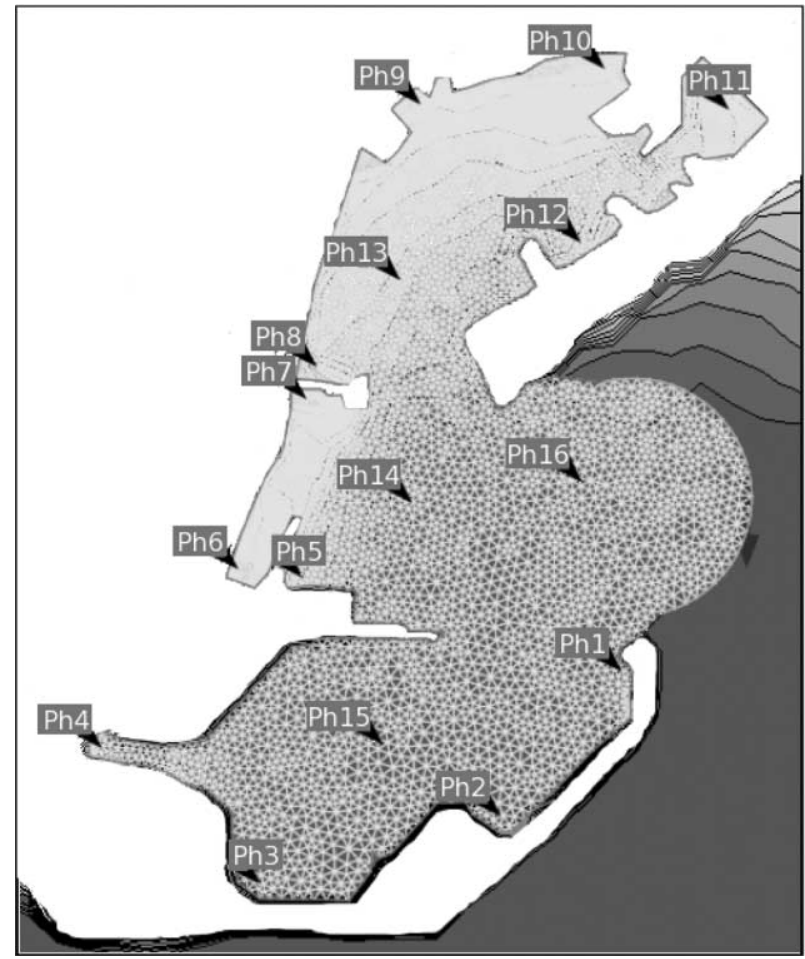

Figure 6. Domain used for Instituto de Hidráulica-mild slope simulations for the harbor of Palma, with location of the selected synthetic points. A color version of this figure is available online.

served good agreement between numerical and analytical results.

COMCOT (Liu et al. 1994, 1995), developed by the School of Civil and Environmental Engineering, Cornell University, is a reference model for tsunami propagation. It has been widely used to investigate the propagation of historical tsunamis such as the 1960 Chilean tsunami (Liu et al. 1994), the 1992 Flores Islands tsunami (Liu et al. 1995), the 2003 western Mediterranean tsunami (Wang and Liu 2005; Álvarez-Gómez et al. 2010), and the 2004 Indian Ocean tsunami (Wang and Liu 2006).

COMCOT solves both nonlinear and linear shallow-water equations, adopting a modified leapfrog scheme. Its nesting capabilities make it possible to simulate tsunami generation and propagation from the source zone to a given coastal area, considering the inundation of coastal zones. A two-way nesting method is applied for the nested grid system. The finer inner grids adopt smaller grid sizes and time steps compared to their adjacent outer (larger) grids. In the outer grids, at the beginning of each time step, the volume flux is interpolated into their inner (finer) grids. At the end of each time step, the calculated water surface elevations at the inner finer grids are averaged to update the free surface elevations of the larger grids, which are used to compute the volume fluxes at the next time step in the coarser grids. This allows the model to capture near-shore features of tsunami propagation with higher grid and time resolution while maintaining computational efficiency (Wang and Liu 2005).

In the western Mediterranean region, earthquake-generated tsunamis are expected to present wave lengths between 225 and $15 \mathrm{~km}$ for water depths between 3000 and $10 \mathrm{~m}$. In these circumstances, wave dynamics can be considered mainly horizontal, with vertical accelerations negligible; thus, the pressure field can be assumed to be hydrostatic (Wang and Liu 2005). Propagation of this kind of waves can be correctly simulated using the shallow-water wave equations that, in a Cartesian coordinate system, can be expressed as the mass conservation equation,

$$
\frac{\partial \zeta}{\partial t}+\frac{\partial P}{\partial x}+\frac{\partial Q}{\partial x}=0
$$

and the momentum conservation equations,

$$
\begin{aligned}
& \frac{\partial P}{\partial t}+\frac{\partial P^{2}}{\partial x}+\frac{\partial P Q}{\partial y}+g H \frac{\partial \zeta}{\partial x}+\tau_{x} H-f Q=0 \\
& \frac{\partial P}{\partial t}+\frac{\partial P Q}{\partial x}+\frac{\partial Q^{2}}{\partial y}+g H \frac{\partial \zeta}{\partial y}+\tau_{y} H-f P=0
\end{aligned}
$$

where $\zeta=$ free surface elevation above mean sea level; $(x, y)=$ longitude and latitude of the earth; $\left(\tau_{\mathrm{x}}, \tau_{\mathrm{y}}\right)=$ bottom shear stress in the $X$-axis (pointing to the east) and $Y$-axis (pointing to the north); $P$ and $Q=$ volume fluxes $(P=h u$ and $Q=h v$, with $u$ and $V$ being the depth-averaged velocities in the longitude and latitude direction); $H=$ total water depth $(=h+\zeta)$, with $h$ being the water depth; and $f=$ the Coriolis parameter.

\section{Sea Level Oscillations in Palma Bay and Palma Harbor}

Observed Sea Level Variations: Tsunami of May 2003. The Palma float tide gauge recorded sea level oscillations caused by the 2003 western Mediterranean tsunami at 1-min intervals (fig. 2A). The gauge is located at the end of the west quay in the Palma harbor, at a depth of about $20 \mathrm{~m}$ (fig. 1).

We presume that the maximum total amplitude of $1.1 \mathrm{~m}$ recorded by the Palma gauge was less than the maximum amplitude achieved in the most damaged areas of the harbor (see "Introduction"). The spectral analysis of the data shows the main peak of energy at a 22-min period, with the three 


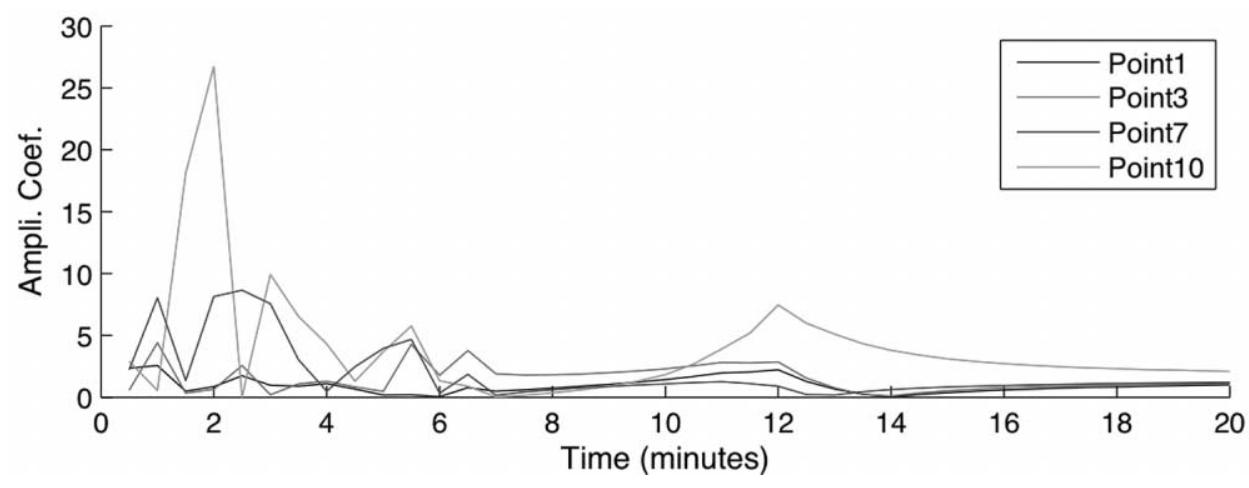

Figure 7. Output of the frequency-swept simulations at selected synthetic points in Palma harbor. Only four representative synthetic points are illustrated to present a clearer plot. A color version of this figure is available online.

most energetic peaks at $19.55,40.35$, and 75.16 min (fig. 2B). The maximum wave amplitude was reached $110 \mathrm{~min}$ after the arrival of the tsunami, which showed initial amplitude of only $20 \mathrm{~cm}$ at the Palma harbor tide gauge. This delay points to the occurrence of local resonance, with the larger amplitudes reached inside the harbor caused by local amplification of the tsunami wave. Such a hypothesis could be checked by performing a study of the natural resonance frequencies of the bay and harbor of Palma by means of numerical simulations, as presented below.

Natural Resonance Frequencies in the Palma Bay and Harbor. Numerical simulations have been performed with the overall aim of determining the natural modes of oscillation and the main frequencies of response to sea level oscillations in Palma bay and harbor by considering their particular geometry and bathymetry. The final step is identifying the origin of the frequencies present in the tide gauge record and determining whether they are a response attributable to the configuration of the bay, the harbor, or both. For this we have generated a finite-element grid with an average grid size of $40 \mathrm{~m}$ in the bay and $10 \mathrm{~m}$ in the harbor and along the coastline (fig. 3).

Palma Bay. The IH-MSP model (see "Methodology") has been forced with a frequency sweep ranging from 0.5 - to 120 -min periods, with $0.5-\mathrm{min}$ increments, in order to identify the resonance frequencies in the grid domain. Total reflection has been imposed over the coastal boundaries as we are studying long waves. The elevation time series for some of the synthetic points that have been se-
A)

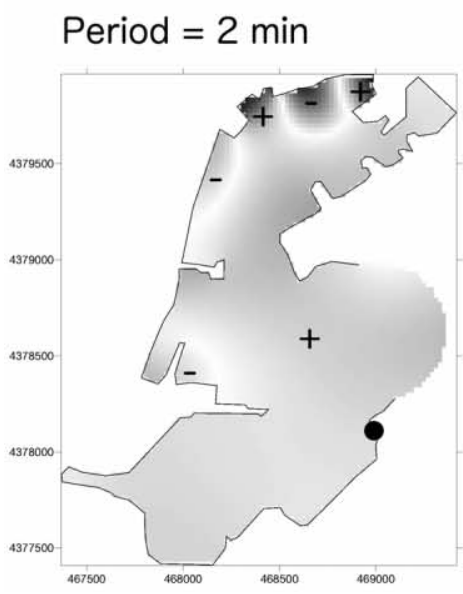

B)

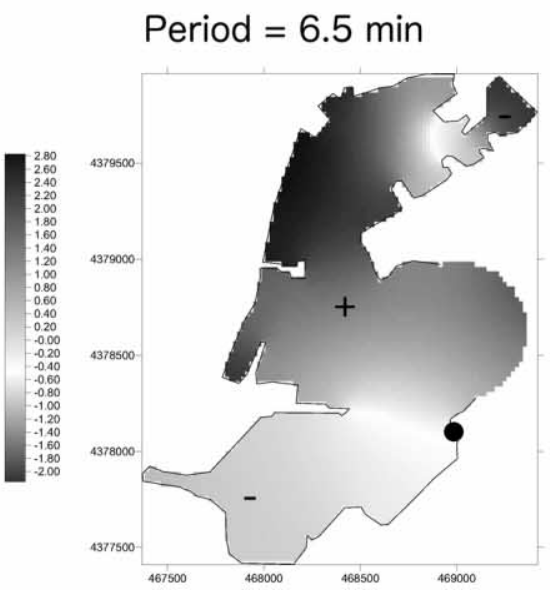

C)

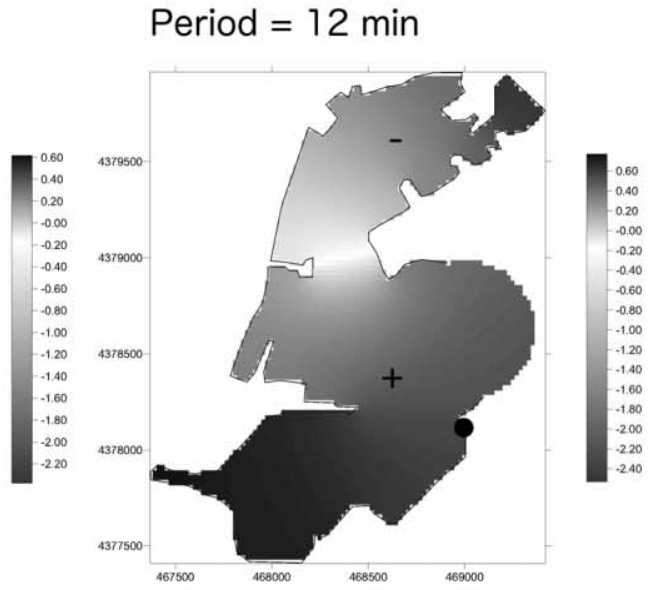

Figure 8. Spatial distribution of nodes and antinodes for the main modes of oscillation identified for Palma harbor. Filled dots indicate tide gauge location. Plus and minus symbols indicate the oscillation sense. $A, 2$-min period. $B$, 6.5 -min period. $C, 12$-min period. A color version of this figure is available online. 
A)

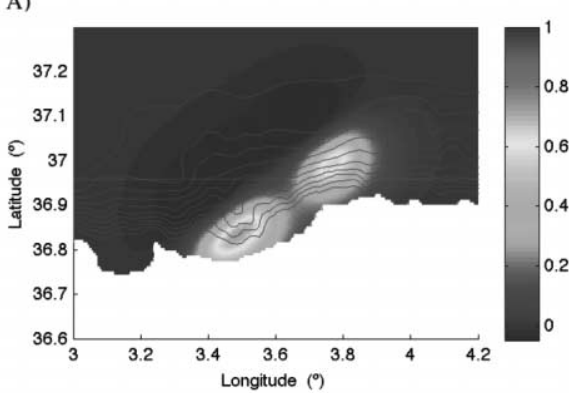

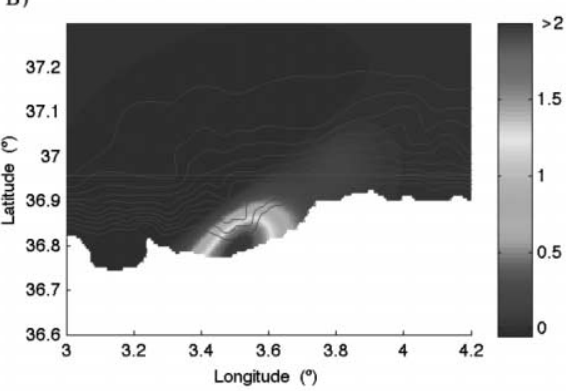

Figure 9. North Algerian seismic sources for the western Mediterranean tsunami. A, Source after Meghraoui et al.'s (2004) parameterization showing vertical displacement close to the epicenter. $B$, Source after Wang and Liu (2005) parameterization. Note that the vertical shading scales in meters are different. A color version of this figure is available online.

lected in the grid domain outside the harbor (fig. 3) are displayed in figure $4 A$. The plot shows that the main peaks correspond to $6.5,13,17,22$, and 41 $\mathrm{min}$. For some of the synthetic points there is also one peak at $9.5 \mathrm{~min}$. The 22 -min mode of oscillation coincides exactly with the most energetic mode recorded by the tide gauge (see "Observed Sea Level Variations: Tsunami of May 2003"). It should be noted that some energy peaks appear for $T<6$ min (fig. 4A) in points located near beach areas (e.g., points $\mathrm{Pb} 5$ and $\mathrm{Pb} 6$ in fig. 3 ).
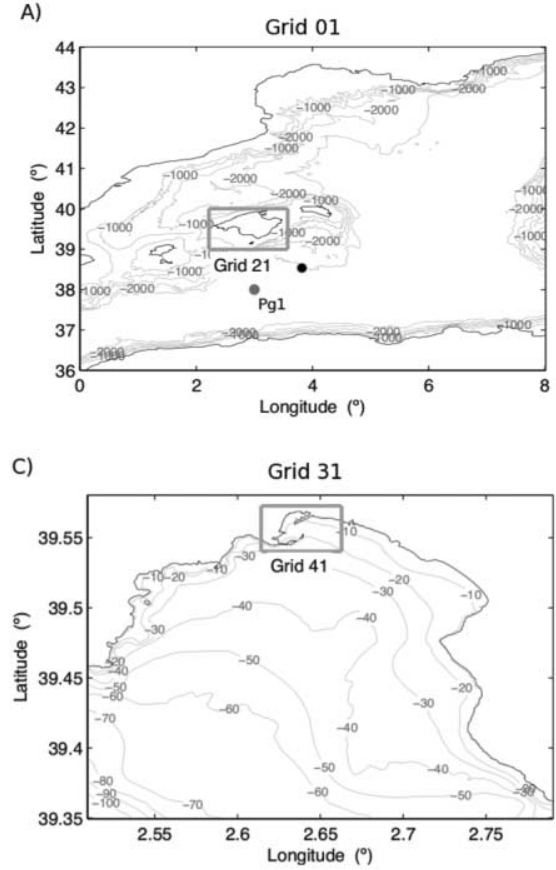

The main peaks inside the harbor, also considered part of the bay grid domain in this simulation, correspond to $9.5,17$, and $22 \mathrm{~min}$, the two latter coinciding with synchronous peaks off harbor (fig. $4 B)$. No significant energy amplifications are obtained for $T>30 \mathrm{~min}$.

The spatial distribution of free surface oscillations (i.e., nodes and antinodes) for the main modes of oscillation within the bay and harbor is shown in figure 5. The 9.5-min period results in N-S and NW-SE oscillation waves, the latter between the

B)

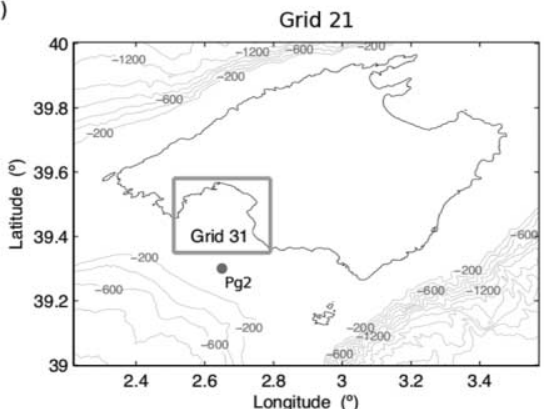

D)

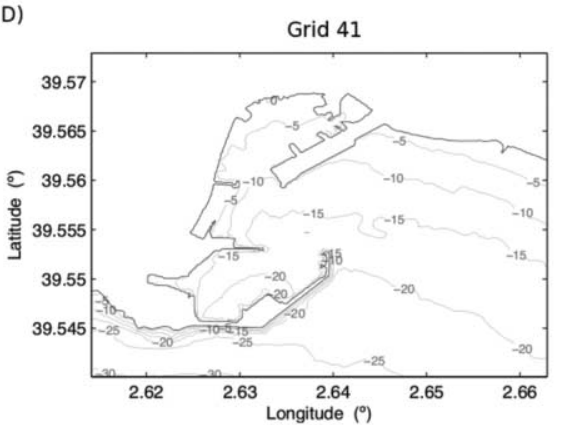

Figure 10. Computational domains considered in the analysis of sensitivity to source parameterization. $A$, Western Mediterranean Basin (grid 01). B, Majorca Island (grid 21). C, Palma de Majorca bay (grid 31). D, Palma harbor (grid 41). Synthetic points Pg1 and Pg2 in grid 01 and grid 21 are located at 2600- and 120-m water depth, respectively. A color version of this figure is available online. 


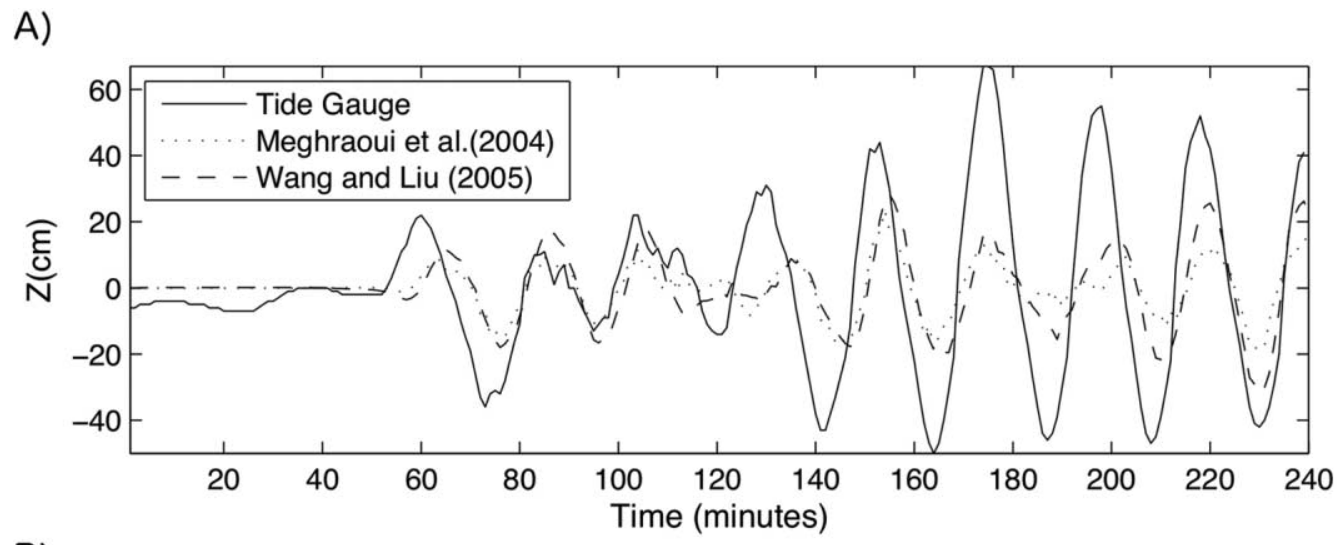

B)

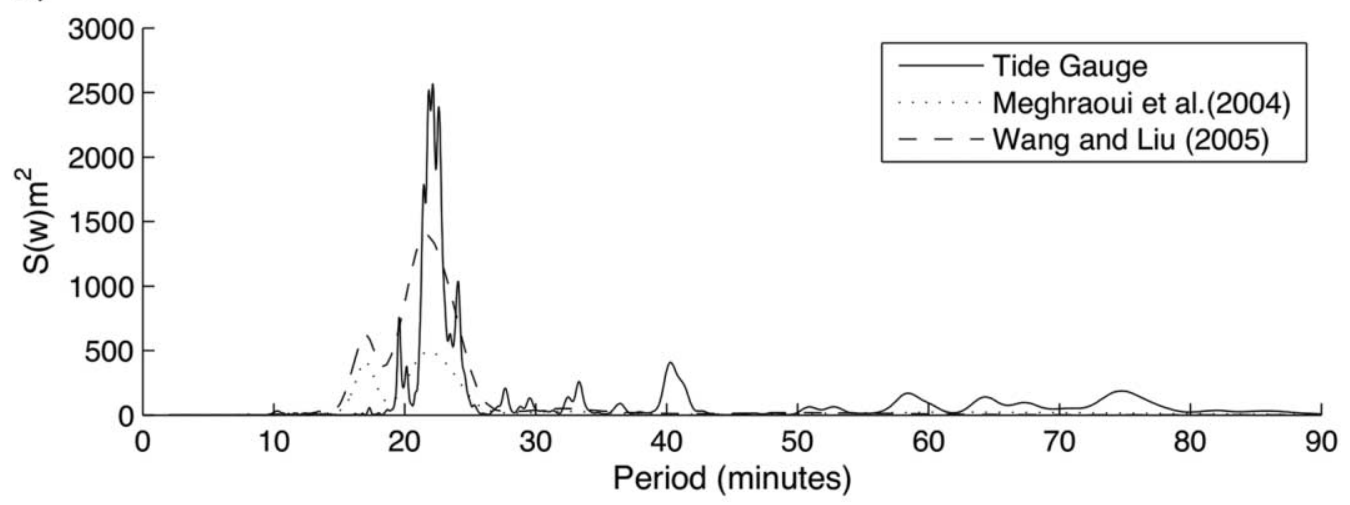

Figure 11. A, Sea level oscillations at the location of the Palma tide gauge from both observation (tide gauge curve) and simulations. $B$, Distribution of spectral energy for sea level oscillations at the location of the Palma tide gauge from both observation (tide gauge curve) and simulations. A color version of this figure is available online.

harbor and the coastline opposite the SE, thus paralleling the sandy beaches closing the bay to the NE. One of the most resonant periods in the bay system (including the harbor) is the 17-min one, with energy amplification being larger outside the harbor, which involves an antinode immediately south of it. Finally, the 22-min period results in a NE-SW-oriented wave oscillation.

We hypothesize that the energy peaks for $T<6$ min obtained for synthetic points in the northeastern beaches (fig. 3) and the NW-SE oscillation wave of the 9.5-min period (fig. 5) are caused by the interaction of the harbor, the beaches themselves, and the local geometry, leading to the generation of transverse or edge waves.

As it could be observed, the location of the Palma tide gauge does not correspond to the highestenergy response to any of the frequencies in figure 5 compared to the northern basin of the harbor. This is an observation to be taken into account when interpreting the results of COMCOT simulations.
Palma Harbor. The same procedure described in the "Palma Bay" subsection has been followed to analyze the natural oscillations induced within the harbor domain with total reflection in breakwaters and boundaries (fig. 6). Figure 7 shows the response at some of the synthetic points leading to the identification of main peaks of energy within the harbor at 2, 3.5, 5.5, 6.5, and 12 min. Frequencies are higher than in the bay, as should be expected considering the smaller size of the harbor domain. Free surface oscillations are illustrated in figure 8 for 2-, 6.5-, and 12-min periods when the maximal oscillations occur at the northern basin where synthetic points $\mathrm{Ph} 9-\mathrm{Ph} 12$ are located. Point Ph10 corresponds to the Sant Magí dock, where serious damages were reported as a result of the 2003 western Mediterranean tsunami (see "Introduction"; figs. 1, 6, 7).

Energy peaks for periods over $12 \mathrm{~min}$ have not been found within the harbor domain. However, simulations at the bay scale show that points located within the harbor domain (i.e., points $\mathrm{Pbl}$ 


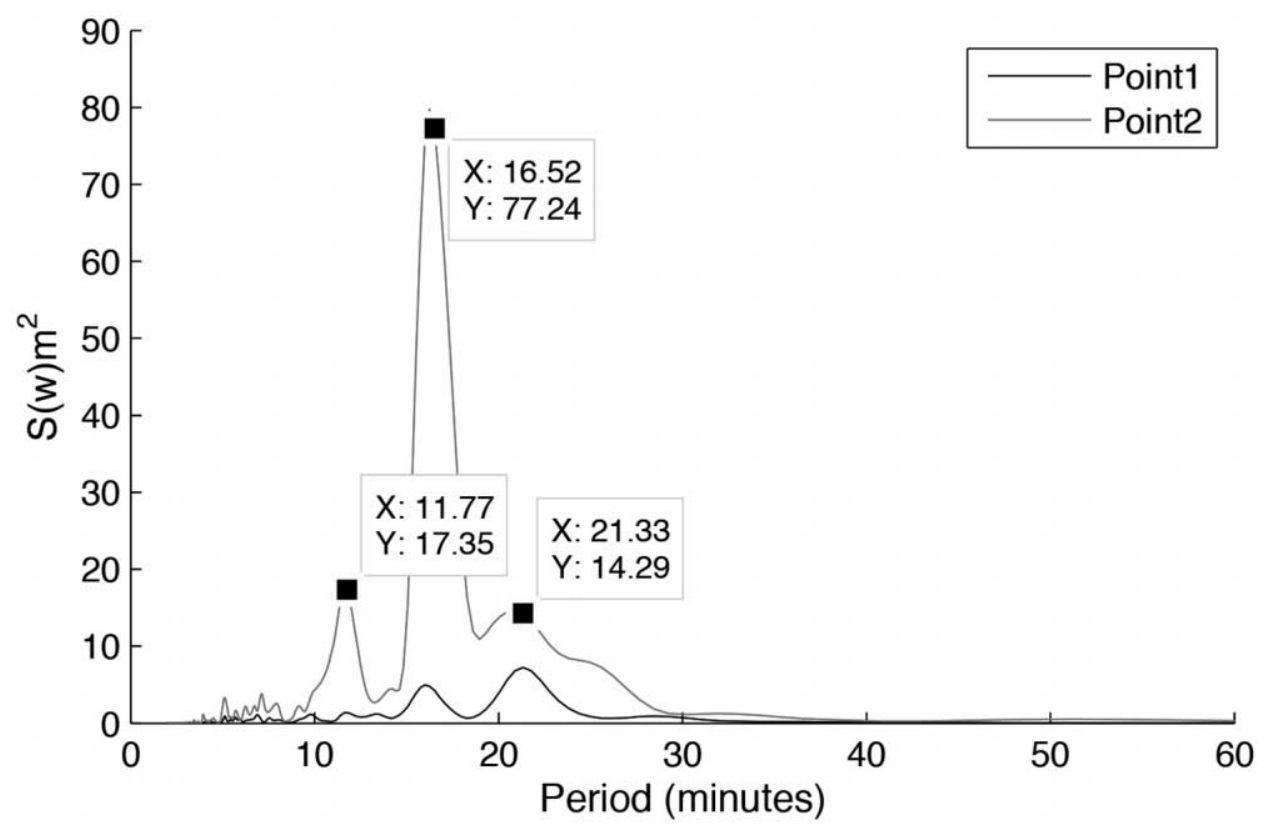

Figure 12. Plot illustrating the influence of the nonlinear effect and local bathymetry on the spectral density of the arriving tsunami wave. There is a clear interaction with the continental shelf that affects the distribution of energy well before entering Palma bay. Point Pg1 is located at 2600-m water depth while point Pg2 is at $120-\mathrm{m}$ depth on the island's shelf. A color version of this figure is available online.

Pb4; see fig. $4 B$ ) present energy at 17 and 22 min, which likely result from coupling between the bay and the harbor. In other words, the 17- and 22-min resonant oscillations are induced by the geometry of the bay in the harbor domain.

The study of the natural resonance frequencies in the Palma bay and harbor shows (i) that the most energetic oscillation periods recorded by the tide gauge (fig. 2B) after the 2003 western Mediterranean tsunami, and especially the one at $22 \mathrm{~min}$, are consistent with the natural modes of oscillations within the bay (fig. $4 B$ ) and (ii) that no apparent resonance is associated with the harbor itself, with resonant periods smaller than $12 \mathrm{~min}$ (fig. 7). This implies that the wave amplification observed inside the harbor, principally in the most damaged northern basin (figs. 5, 8), was generated by a resonance effect induced by the Palma bay.

Our results confirm the idea that the Palma tide gauge measurements did not reflect the actual magnitude and impact of the 2003 western Mediterranean tsunami in the theoretically more protected northern basin of the harbor. This is because (i) the 1 -min recording interval of the tide gauge poorly recorded the 2-min frequency of the most energetic peak in the harbor domain (fig. 7) and (ii) the maximum oscillation occurring in the Sant Magí dock of the harbor's northern basin (fig. 1) was less significant at the tide gauge position.

\section{Sensitivity Analyses}

To check the robustness of the above-presented results, we carried out a double sensitivity analysis: to source parameterization and to bathymetric grid resolution, whose outcome is presented below.

Sensitivity to Source Parameterizations. Since uncertainties in the source fault parameters may produce differences in both the wave height and the period of the tsunami, we carried out a sensitivity analysis to source parameterization for the 2003 western Mediterranean tsunami. To this purpose two different simulations with COMCOT were performed for the following parameterizations of the seismic source: (i) after Meghraoui et al. (2004), with a magnitude of $6.8,50 \mathrm{~cm}$ of vertical displacement, and (ii) after Wang and Liu (2005) following correction with tide gauge data with a magnitude of 7.2 and $2.2 \mathrm{~m}$ of vertical displacement.

In both cases, the tsunami generation mechanism adopts the model of Mansinha and Smylie (1971), assuming that the instantaneous sea surface deformation is equal to the seafloor deformation. Wang and Liu's (2005) observation that previous 


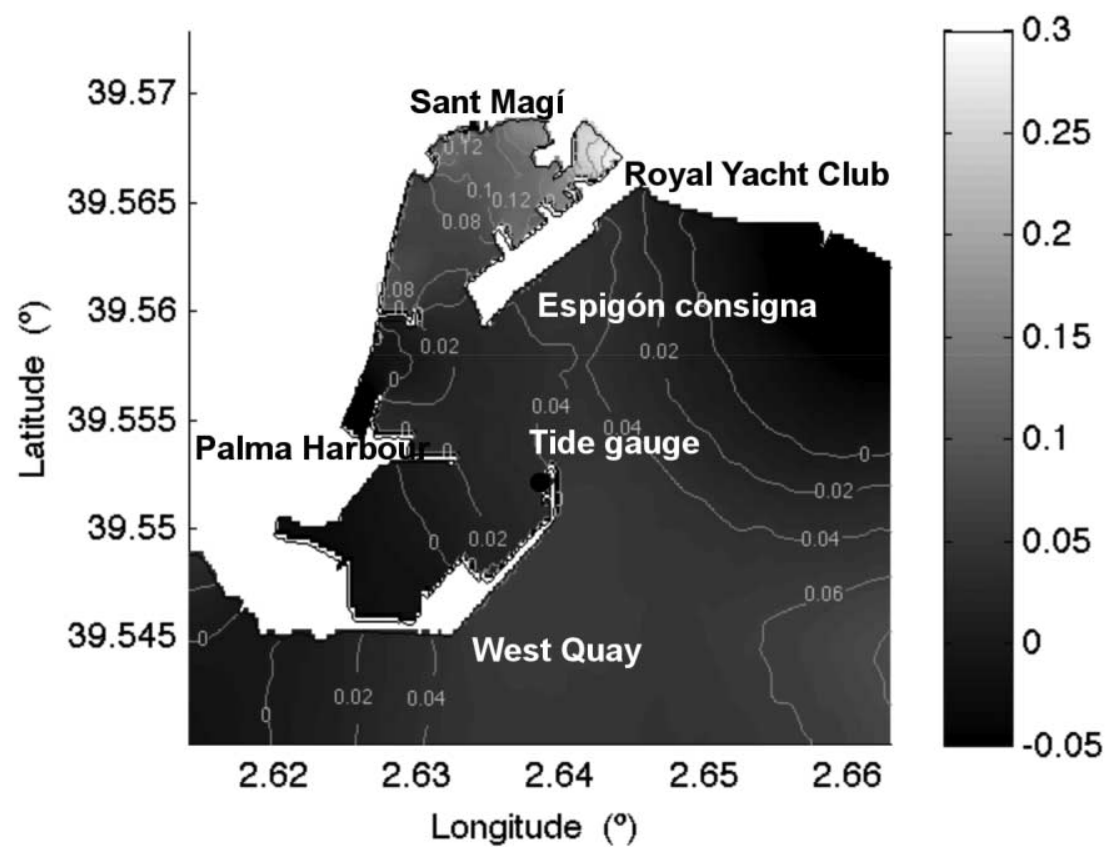

Figure 13. Spatial distribution of maximum amplitudes following Meghraoui et al.'s (2004) parameterization during the highest range of the simulations (approximate time, $162 \mathrm{~min}$ ) showing highest values in the northern basin of the harbor. The area close to the tide gauge displays low amplitudes in the simulations. Vertical shading scale in meters. A color version of this figure is available online.

parameterizations had underestimated the tsunami wave height led them to apply an inverse method to determine seafloor vertical displacement using sea level records from Eivissa city and Sant Antoni tide gauges, which resulted in a significant difference with respect to Meghraoui et al.'s (2004) estimation: $2.2 \mathrm{~m}$ against $0.5 \mathrm{~m}$ of seafloor offset (fig. 9; see also "Introduction").

Table 1 and figure 10 show the four different nested bathymetric grids used for both simulations, ranging in resolution from $720 \mathrm{~m}$ (grid 01 in fig. $10 A$ ) to $20 \mathrm{~m}$ (grid 41 in fig. $10 D$ ) inside the harbor. The bathymetric grids were produced by the University of Barcelona after compiling the best available information from open-access databases and bathymetric maps, the Spanish exclusive economic zone program, nautical charts of the Balearic Islands of the government of the Balearic Islands, proprietary information, and Puertos del Estado. The nonlinear equations were selected for the three inner grids and the linear approximation for the most external grid.

The two sources, significantly differing both in magnitude of the earthquake and in vertical displacement of the seafloor, underestimate the tsunami amplitude measured at the Palma tide gauge, as illustrated by the plot corresponding to the synthetic point closest to the tide gauge station (figs. $11,12)$, as previously noticed by Wang and Liu (2005) and Alasset et al. (2006). Although the Wang and Liu (2005) source improves the energy and amplitude of the oscillations compared to Meghraoui et al. (2004), still is significantly lower than the one observed at the harbor. In fact, the model results in a small variation of the harbor response to a significant change in the source parameters (i.e., from 0.5 to $2.2 \mathrm{~m}$ of vertical displacement).

Also, the time series plot at the tide gauge position shows a 5-min delay in the arrival of the first tsunami wave from the simulations, if compared with observations (fig. 11A). Wang and Liu (2005) and Alasset et al. (2006) found the same delay. In contrast, no delay between simulations and observations was identified in Eivissa city and Sant Antoni, in the nearby island of Eivissa. Possible explanations for such an anomaly could be a malfunctioning of the tide gauge's clock (though several clock adjustment trials did not solve the problem) or a wrong exact location of the source.

An interesting outcome is that the most damaged areas inside the harbor (i.e., the northern basin) do correspond to the highest amplitudes from the sim- 


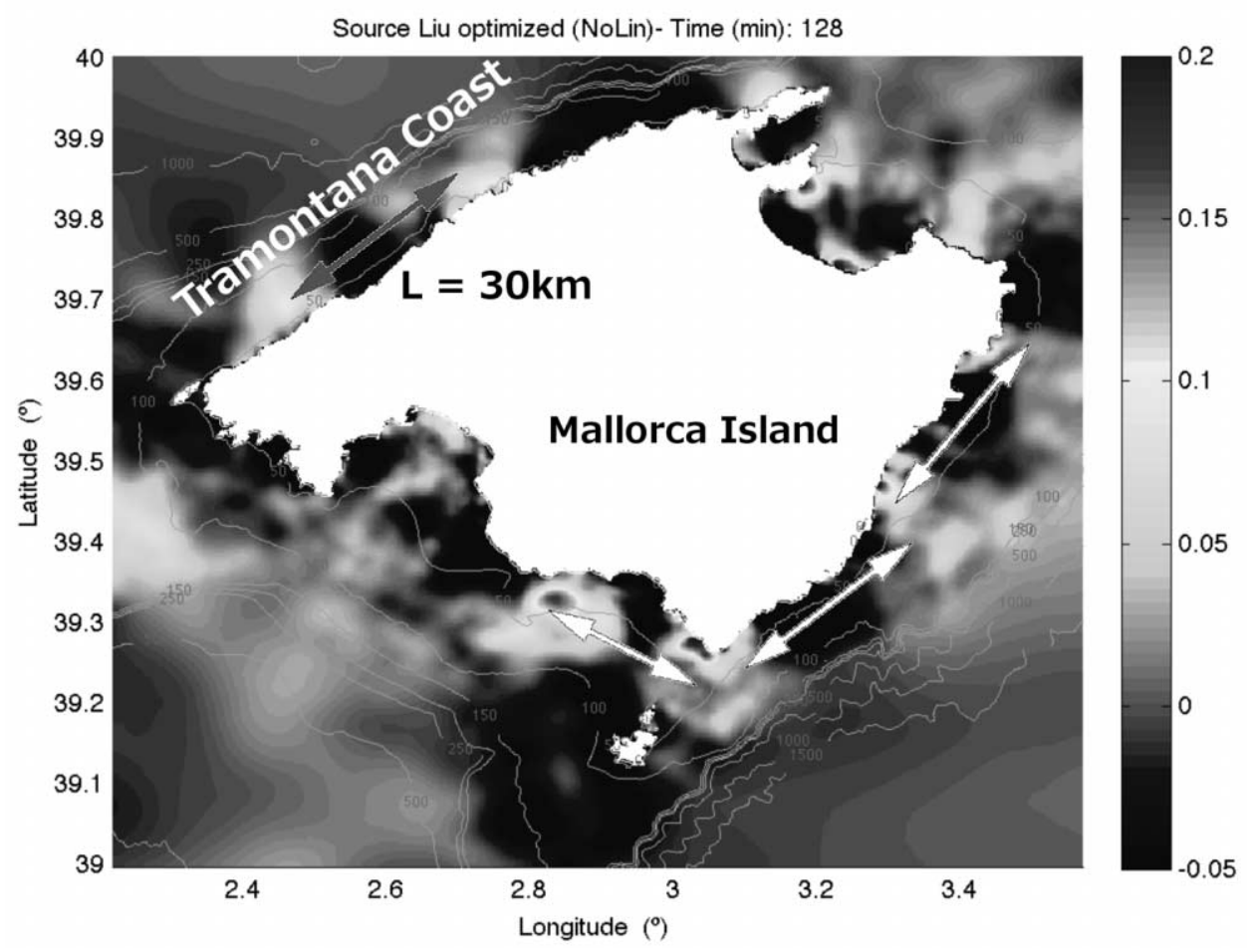

Figure 14. Output from one of the simulations at time $128 \mathrm{~min}$ showing the presence of edge waves propagating around the island with an approximate period of $12-14 \mathrm{~min}$ and $30 \mathrm{~km}$ of wavelength in the northern Tramontana coast. A color version of this figure is available online.

ulations (fig. 13). The simulations indicate that the maximum level stays around $3 \mathrm{~min}$ at Sant Magí dock.

Noticeable oscillations remain even $3 \mathrm{~h}$ after the leading tsunami wave reaches the harbor (minutes 220,240 of the simulation), which is consistent with observations. This effect is attributed to a resonance phenomenon with an approximated period of $22 \mathrm{~min}$ (fig. 11A) that appears in both the simulations and the observations and coincides with the second natural oscillation mode of Palma bay, as explained before. None of the simulations shows the smaller peaks around 40.45 and $74.47 \mathrm{~min}$ found in the tide gauge data (fig. $11 B$ ), which likely result from interactions between the islands' shores and the continental shelf. Longer simulation times would be required to obtain such long periods. However, both numerical simulations display a peak at $17 \mathrm{~min}$ that, in addition to being close to the 19-min small peak in the observations, roughly coincides with the third mode of natural oscillation of the bay (i.e., $17 \mathrm{~min}$ ). A likely explanation for the latter is that the third mode (17 min) of natural oscillation of the bay produces a node close to the position of the tide gauge, while the second mode
(22 min) shows an antinode at this point (fig. 5). Furthermore, the 22-min peak is broader and easier to excite than the 17-min peak. The fact that these two modes of natural oscillation have antinodes at the most internal part of the harbor, in the northern basin, also explains why the amplitude of the waves and the most serious damage occurred precisely there (see "Sea Level Oscillations in Palma Bay and Palma Harbor").

Further insight could be obtained after considering the spectral density of synthetic points from the simulations in open waters. In this case we considered two points, Pg1 and Pg2, located outside the shelf at a water depth of $2600 \mathrm{~m}$ (and on the shelf south of Palma bay at 120-m water depth, respectively; fig. 10). The abrupt change in water depth generates fission and peaking of the first soliton, resulting in new energy high frequencies (i.e., small solitons with smaller periods). Losada et al. (2008) attributed this behavior to reflection and energy loss effects and to nonlinear and dispersive effects. It is worth noticing that the $17-\mathrm{min}$ peak is hugely enhanced, that the 22-min peak is barely reinforced, and that an additional peak of $12 \mathrm{~min}$ appears that is not present in open waters (fig. 12). 


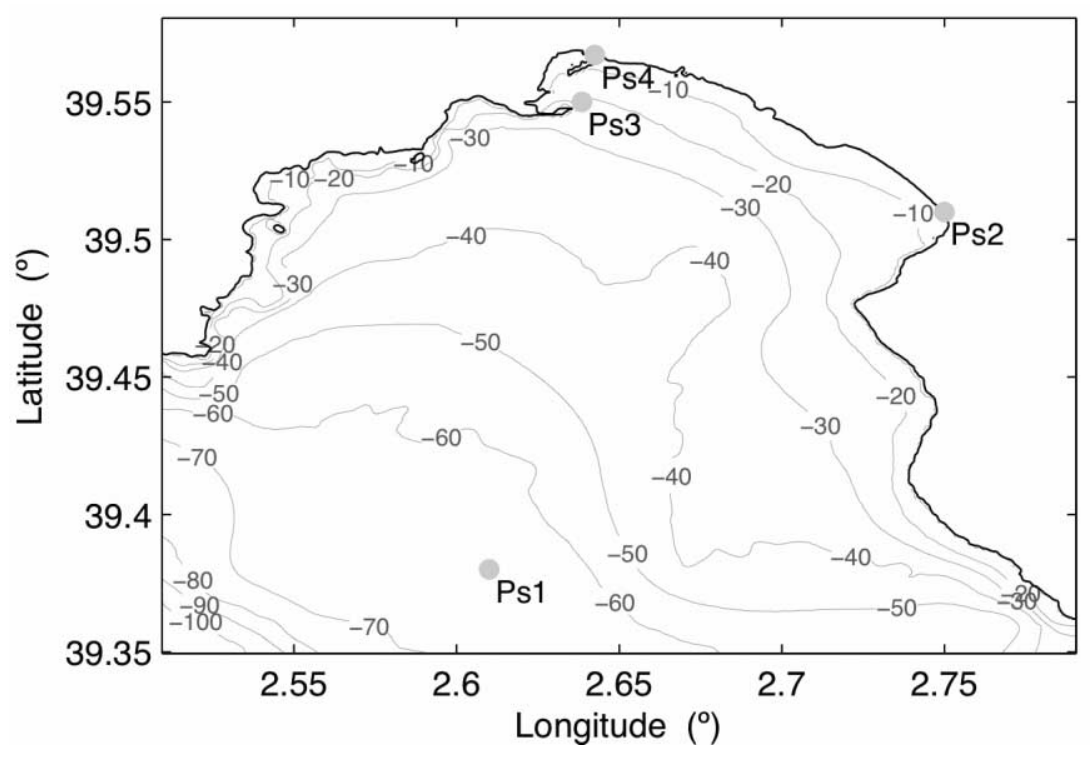

Figure 15. Inner grid for the sensitivity experiment to increasing bathymetric resolution, showing the location of the synthetic points selected for displaying the results. See figure $1 B$ to locate the bay. A color version of this figure is available online.

The 12-min peak could be associated with edge waves generated along the island's shelf, which have been identified in the simulations, as shown in figure 14. The estimated wavelength of these edge waves along the northern Tramontana coast of Majorca is around $20-30 \mathrm{~km}$. It should be noted that this period, which appears in the simulations, does not seem to be of significance in the Palma bay and harbor as inferred from the tide gauge spectra, but it could be of relevance for beaches and small embayments along the island's coast.

The energy amplification for the 17-min period could be induced by the shoaling effect of tsunami waves traveling over the shelf and/or by resonance effects due to the bay's geometry, as the $17-\mathrm{min}$ period is a significant natural oscillation period for Palma bay (fig. $4 B$ ). The amplification factor $\left(K_{\mathrm{a}}\right)$ in terms of wave height (but not energy; $\sim H^{2}$ ) from the outer point Pgl with a wave height $H_{\mathrm{e}}$ with respect to the point $\mathrm{Pg} 2$ over the shelf with wave height $H_{\mathrm{s}}$ is $K_{\mathrm{a}}=4\left(K_{\mathrm{a}}=H_{\mathrm{s}} / H_{\mathrm{e}}\right)$. Wave amplification due to shoaling can be expressed by the coefficient $\left(K_{\mathrm{s}}\right)$, which is obtained applying Green's law $\left(K_{\mathrm{s}}=\left(h_{\mathrm{e}} / h_{\mathrm{s}}\right)^{1 / 4}\right)$, where $h_{\mathrm{e}}$ and $h_{\mathrm{s}}$ are the water depths at P1 and P2 $\left(h_{\mathrm{e}}=2600 \mathrm{~m}\right.$ and $h_{\mathrm{s}}=120$ $\mathrm{m})$; so, in this case the shoaling coefficient is $K_{\mathrm{s}}=$ 2 . This means that a resonance effect has been generated as induced by the bay and local interactions over the shelf to obtain an amplification in the wave height of $K_{\mathrm{a}}=4$. The resonance effect in the 17-min period is further confirmed by the fact that for the propagation of the 22-min period, the amplification factor obtained from figure 12 is $K_{\mathrm{a}}=$ 1.8 , which is very close to the shoaling $K_{\mathrm{s}}=2$. This demonstrates that the 22-min period does not experience resonance effects compared to the 17-min period.

From the above results it can be stated that the small energy component within the 17-min period coming with the tsunami wave (fig. 12) is largely amplified by wave shoaling caused by abrupt bathymetry change at the island's shelf, combined with a resonance effect induced by the bay, which also has a natural oscillation mode of $17 \mathrm{~min}$ (fig. $4 B)$. In addition, solitons with smaller periods $(T<$ $10 \mathrm{~min}$; fig. 12) are generated over the shelf when the tsunami propagates from 2600 to $120 \mathrm{~m}$ of water depth. Finally, the 12-min period detected over the shelf is associated with edge waves traveling along the island shelf (fig. 14) whose influence likely is larger on beaches and small embayments along the shoreline than at Palma bay and harbor, where the energy amplification is small despite having a natural oscillation mode close to this frequency.

Sensitivity to Bathymetric Grid Resolution. A second factor that could lead to the underestimation of tsunami wave heights is the resolution of the bathymetric grids utilized for the simulations. Therefore, we performed a sensitivity test of the 
A)

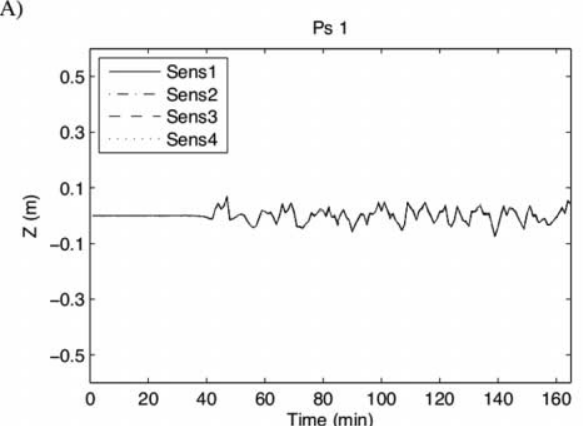

C)

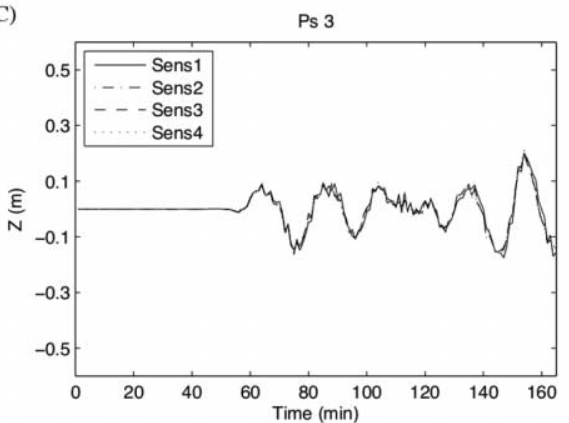

B)

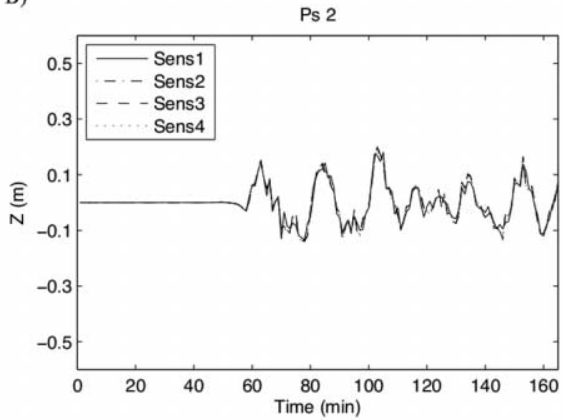

D)

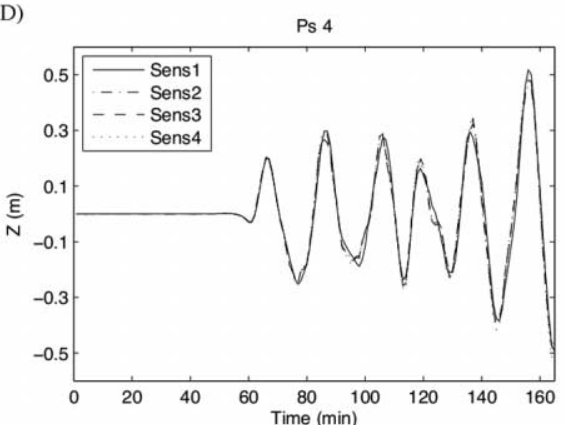

Figure 16. Sea level output at the synthetic points in figure 15 for the sensitivity experiment to bathymetric resolution for the four different simulations. A, Point Ps1. B, Point Ps2. C, Point Ps3. D, Point Ps4. A color version of this figure is available online.

model to the increase of grid resolution in the Palma bay and harbor and also carefully checked the boundaries inside the harbor. To undertake this exercise we applied Meghraoui et al. (2004). Table 2 shows the four different configurations selected for this new exercise, which are applied to grids 01, 21 , and 31 in figure 10 . Since the latter grid already included both the bay and the harbor, just three nested grids were considered, with an increasing resolution of the inner one for each of the four simulations. In all cases we utilized the linear approximation for the outer grids, keeping the nonlinear approximation only for the bay and harbor grid (table 2). Each configuration involves a different resolution of the inner grid, from $111 \mathrm{~m}$ (Sens1) to 16 $\mathrm{m}$ (Sens4). For the purpose of comparison, no bottom friction was included in the simulations.

Four synthetic tide gauges located at points Ps1Ps4 were processed to extract the sea level and the energy spectra (fig. 15). The first point, Ps1, placed at the entrance of Palma bay, allowed detecting the incoming wave from open waters affected only by the continental shelf bathymetry. The other synthetic points were placed at strategic locations: Ps2 on the northern shore of the bay opposite the har- bor, Ps3 inside the harbor at the same location of the actual tide gauge, and Ps4 on the inner basin of the harbor where the tsunami amplitude was larger.

The differences among the four simulations can be examined in sea level elevation and energy spectral density plots (figs. 16, 17). Of course, it may happen that sea level computed in a synthetic point does not fit in all the simulations, but the spread of energy in the same frequencies with the same magnitude in all cases indicates that bathymetric resolution has no significant influence on the sensitivity of the simulations (fig. 17).

The analysis of sensitivity to bathymetric grid resolution, taking into account the actual harbor geometry and the configuration of inner structures, shows that the harbor responds with a wave height increment to increased resolution in the bay and the harbor domains but also shows that such an increment is insufficient to obtain the wave heights registered by the tidal gauge.

Therefore, bay and harbor geometry is not the relevant source of wave height underestimation by the simulations in this case. However, simulations do illustrate a similar behavior in the harbor com- 
A)
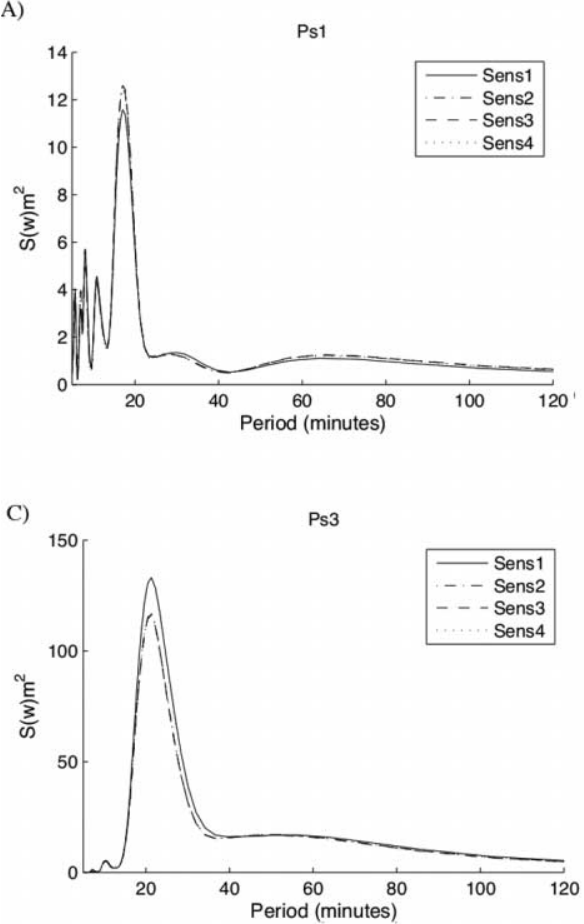
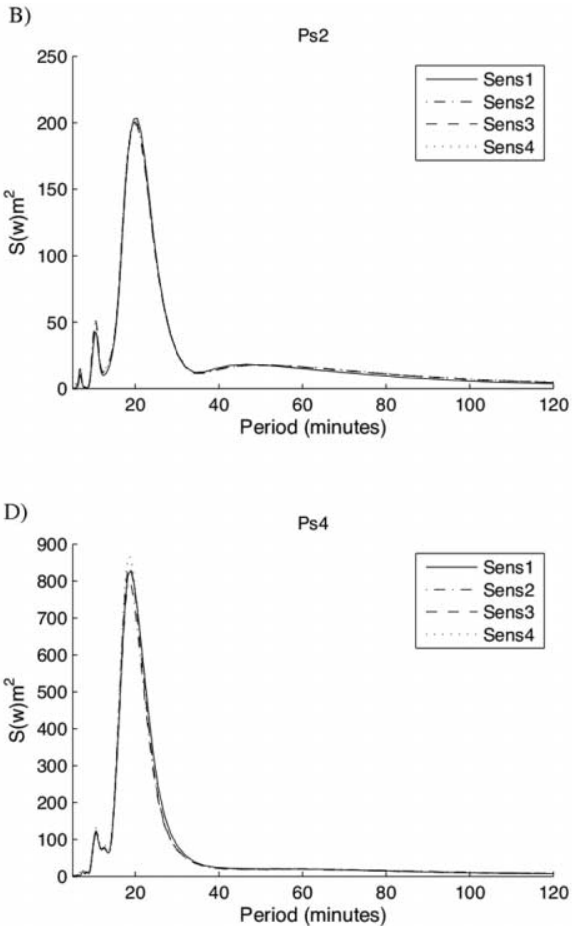

Figure 17. Spectral density for the synthetic points in figure 15 for the sensitivity experiment to bathymetric resolution for the four different simulations. A, Point Ps1. B, Point Ps2. C, Point Ps3. D, Point Ps4. A color version of this figure is available online.

pared to tidal gauge measurements (point Ps3), with a maximum wave height at $150-160 \mathrm{~min}$ in figure 16 that is relatively close to the 110 min after the earthquake in the gauge record. Furthermore, point Ps4 in the northern basin of the Palma harbor presents wave heights around $1 \mathrm{~m}$ in simulations, which are almost three times higher than the wave height in the tide gauge at Ps3 (fig. 16). Eyewitnesses confirm such substantial wave amplification in the harbor's northern basin during the 2003 event. Overall, the present situation, including underestimation of wave amplitudes but similar spatial and temporal behavior among simulations and observations, suggests that the seismic source parameters should be revised.

\section{Conclusions}

We have presented the results of a numerical study aimed at better understanding the response of the interacting Palma bay and harbor under the impact of the 2003 western Mediterranean tsunami. The transference of the tsunami energy from the generation area to the continental shelf, the bay, and the harbor has been studied and compared with the natural oscillation modes of the bay and harbor wa- ter bodies, as well as a sensitivity analysis of the source parameterization and the bathymetry grid size for the bay and harbor.

Energy from the 2003 western Mediterranean tsunami, as measured by the tidal gauge of Palma harbor, concentrated mainly in 19- and 22-min periods (fig. $2 B$ ). These periods are close to the natural modes of oscillations of the bay (fig. $4 B$ ). No resonance appears to be associated with the harbor itself, with resonance periods less than $12 \mathrm{~min}$ (fig. 7). Therefore, we conclude that the observed wave amplification inside the harbor, principally in the northern basin (figs. 5, 8), was generated by a resonance effect induced by the Palma bay configuration. The harbor's northern basin corresponds to the most seriously damaged area according to the harbor authority accounts.

The most energetic peak in the harbor occurred at 2 min or even less (fig. 7), which would be poorly recorded by a 1-min sampling interval by the tide gauge. In addition, the maximum oscillation in the northern basin is lessened at the location of the tide gauge, as illustrated by both the bay and harbor domain experiments. It could then be concluded that, even if remarkable, the Palma tide gauge record does not show in full the actual magnitude of 
Table 2. Parameters of the Four Configurations of the Bathymetric Grids Utilized to Test the Sensitivity of the Cornell Multi-grid Coupled Tsunami Model (COMCOT) to Bathymetric Resolution

\begin{tabular}{|c|c|c|c|c|c|c|c|}
\hline \multirow[b]{2}{*}{ Simulation } & \multicolumn{3}{|c|}{ Grid } & \multirow[b]{2}{*}{ Nodes in $x$} & \multirow[b]{2}{*}{ Nodes in $y$} & \multirow[b]{2}{*}{ Theory } & \multirow[b]{2}{*}{ Roughness } \\
\hline & Name & $\Delta x(\mathrm{~m})$ & $\Delta t(\mathrm{~s})$ & & & & \\
\hline Sens 1 & 01 & 667 & .2 & 1336 & 1336 & Linear & No \\
\hline Sens 1 & 21 & 222 & .1 & 678 & 504 & Linear & No \\
\hline Sens 1 & 31 & 111 & .05 & 282 & 232 & Nonlinear & No \\
\hline Sens 2 & 01 & 667 & .2 & 1336 & 1336 & Linear & No \\
\hline Sens 2 & 21 & 222 & .1 & 678 & 504 & Linear & No \\
\hline Sens 2 & 31 & 37 & .05 & 846 & 696 & Nonlinear & No \\
\hline Sens 3 & 01 & 667 & .2 & 1336 & 1336 & Linear & No \\
\hline Sens 3 & 21 & 222 & .1 & 678 & 504 & Linear & No \\
\hline Sens 3 & 31 & 22 & .05 & 1410 & 1160 & Nonlinear & No \\
\hline Sens 4 & 01 & 667 & .2 & 1336 & 1336 & Linear & No \\
\hline Sens 4 & 21 & 222 & .1 & 678 & 504 & Linear & No \\
\hline Sens 4 & 31 & 16 & .05 & 1974 & 1624 & Nonlinear & No \\
\hline
\end{tabular}

the 2003 tsunami at the harbor's dead end. Furthermore, the low-period energy peaks within the bay $(T<6 \mathrm{~min})$ are associated with a coupling between the harbor and the local geometry in the bay's beach area.

The small energy component at 17 min coming with the tsunami (fig. 12) was amplified by wave shoaling due to the abrupt bathymetry change from the deep basin to the Baleares continental shelf, combined with a resonance effect induced by the bay, one of whose natural oscillation modes is also 17 min (fig. 4B). In addition, solitons with smaller periods $(T<10 \mathrm{~min}$; fig. 16) are generated over the shelf when a tsunami propagates from 2600- to 120 $\mathrm{m}$ water depths. Finally, the 12-min period detected over the shelf is associated with edge waves traveling along the island's shelf (fig. 14), likely with noticeable influence on beaches and small embayments along the coast instead of the bay and harbor. It must be noted that even if the bay and harbor have a natural oscillation mode close to this frequency, energy amplification is small.

Increasing the grid resolution in the bay and harbor domains, and taking into account the actual harbor geometry and inner configuration of structures, does not result in a substantially different response of the harbor tide gauge in the numerical simulations. No significant wave height increment is obtained that would permit a good fit of the simulations with the actual measurements. However, the simulated spatial and temporal behaviors are similar to the ones observed, which points to the need for revising the 2003 tsunami source parameters, in regard to the dimensions of the earthquake or clarification of the existence of a landslide.

\section{A C K N O W LE D G M E N T S}

This work is a contribution from the European Union-funded research project Tsunami Risk and Strategies for the European Region (TRANSFER, ref. 037058). M. Canals and J. L. Casamor acknowledge Generalitat de Catalunya support to Consolidated Research Group Marine Geosciences as an excellence research group (ref. 2009 SGR 1305). Sea level data from the Palma tide gauge have been kindly provided by Instituto Español de Oceanografía.

\section{REFEREN CES CITED}

Alasset, P.-J.; Hebert, H.; Maouche, S.; Calbini, V.; and Meghraoui, M. 2006. The tsunami induced by the 2003 Zemmouri earthquake ( $\mathrm{MW}=6.9$, Algeria): modelling and results. Geophys. J. Int. 166:213-226.

Álvarez-Gómez, J. A.; Olabarrieta, M.; González, M.; Otero, L.; Carreño, E.; and Martínez-Solares, J. M. 2010. The impact of tsunamis on the island of Majorca induced by north Argelian seismic sources. Turk. J. Earth Sci. 19:367-383.

Behrendt, L., and Jonsson, I. G. 1984. The physical basis of the mild-slope wave equation. Proc. Int. Conf. Coast. Eng. 19:941-954.
Berkhoff, J. C. W. 1972. Computation of combined refraction-diffraction. Proc. Int. Conf. Coast. Eng. 13: 471-490.

-1982. Verification computations with linear wave: propagation models. Report W 154-VIII. Delft Hydraulics Laboratory, Delft, Netherlands.

Dan, G. 2007. Processus gravitaires et évaluation de la stabilité des pentes: approche géologique et géotechnique: application à la marge algérienne et à l'effondrement de l'aéroport de Nice en 1979. PhD thesis, Université de Bretagne Occidentale.

Delouis, B.; Vallee, M.; Meghraoui, M.; Calais, E.; 
Maouche, S.; Lammali, K.; Mahsas, A.; Briole, P.; Benhamouda, F.; and Yelles, K. 2004. Slip distribution of the 2003 Boumerdes-Zemmouri earthquake, Algeria, from teleseismic, GPS, and coastal uplift data. Geophys. Res. Lett. 31:L18607. doi:10.1029 /2004GL020687.

Jansa, A.; Monserrat, S.; and Gomis, D. 2007. The Rissaga of 15 June 2006 in Ciutadella (Menorca), a meteorological tsunami. Adv. Geosci. 12:1-4.

Liu, P. L.-F.; Cho, Y.-S.; Briggs, M. J.; Synolakis, C. E.; and Kanoglu, U. 1995. Run-up of solitary waves on a circular island. J. Fluid Mech. 302:259-285.

Liu, P. L.-F.; Cho, Y.-S.; Yoon, S.-B.; and Seo, S.-N. 1994. Numerical simulations of the 1960 Chilean tsunami propagation and inundation at Hilo, Hawaii. In ElSabh, M. I., ed. Recent developments in tsunami research. Dordrecht, Kluwer Academic, p. 99-115.

Losada, I. J.; Gonzalez-Ondina, J. M.; Diaz-Hernandez, G.; and Gonzalez, E. M. 2008. Numerical modeling of nonlinear resonance of semi-enclosed water bodies: description and experimental validation. Coast. Eng. 55:21-34.

Losada, M.; Vidal, C.; and Medina, R. 1989. Experimental study of the evolution of a solitary wave at an abrupt junction. J. Geophys. Res. 94:14,557-14,566.

Mansinha, L., and Smylie, D. E. 1971. The displacement fields of inclined faults. Bull. Seismol. Soc. Am. 61: 1433-1440.

Meghraoui, M.; Maouche, S.; Chemaa, B.; Cakir, Z.;
Aoudia, A.; Harbi, A.; Alasset, J.-P.; Ayadi, A.; Bouhadad, Y.; and Benhamoud, F. 2004. Coastal uplift and thrust faulting associated with the $\mathrm{Mw}=6.8 \mathrm{Zem}$ mouri (Algeria) earthquake of 21 May. Geophys. Res. Lett. 31:L19605. doi:10.1029/2004GL020466.

Monserrat, S.; Vilibic, I.; and Rabinovich, A. B. 2006. Meteotsunamis: atmospherically induced destructive ocean waves in the tsunami frequency band. Nat. Hazards Earth Syst. Sci. 6:1035-1051

Sahal, A.; Roger, J.; Allgeyer, S.; Lemaire, B.; Hébert, H.; Schindelé, F.; and Lavigne, F. 2009. The tsunami triggered by the 21 May 2003 Boumerdès-Zemmouri (Algeria) earthquake: field investigations on the French Mediterranean coast and tsunami modelling. Nat. Hazards Earth Syst. Sci. 9:1823-1834. doi:10.5194 /nhess-9-1823-2009.

Wang, X., and Liu, P. L.-F. 2005. A numerical investigation of Boumerdes-Zemmouri (Algeria) earthquake and tsunami. Comput. Model. Eng. Sci. 10:171-183.

. 2006. An analysis of 2004 Sumatra earthquake fault plane mechanisms and Indian Ocean tsunami. J. Hydraul. Res. 44:147-154.

Yagi, Y. 2003. Source process of large and significant earthquakes in 2003. Bull. Int. Inst. Seismol. Earthq. Eng., p. 145-153.

Yalciner, A. C., and Pelinovsky, E. 2007. A short cut numerical method for determination of resonance periods of free oscillations in irregular shaped basins. Ocean Eng. 34:747-757. 